\title{
Dynamometry for the measurement of grip, pinch, and trunk muscles strength in subjects with subacute stroke: reliability and different number of trials
}

Larissa T. Aguiar ${ }^{1}$, Júlia C. Martins' ${ }^{1}$,Eliza M. Lara ${ }^{1}$, Julianna A. Albuquerque ${ }^{1}$, Luci F. Teixeira-Salmela ${ }^{1}$, Christina D. C. M. Faria ${ }^{1}$

\begin{abstract}
Background: Muscle strength is usually measured in individuals with stroke with Portable dynamometers (gold standard). However, no studies have investigated the reliability, the standard error of measurement (SEM) and the minimal detectable difference $\left(\mathrm{MDD}_{95 \%}\right)$ of the dynamometry for the measurement of hand grip, pinch grip and trunk strength in subjects with subacute stroke. Objective: 1) To investigate the intra and inter-rater reliability, the SEM and the $\mathrm{MDD}_{95 \%}$ of the portable dynamometers for the measurement of grip, pinch and trunk strength in subjects with subacute stroke, and 2) to verify whether the use of different number of trials (first trial and the average of the first two and three trials) affected the results. Method: 32 subjects with subacute stroke (time since stroke onset: 3.6 months, $\mathrm{SD}=0.66$ months) were evaluated. Hand grip, 3 pinch grips (i.e. pulp-to-pulp/palmar/lateral) and 4 trunk muscles (i.e. flexors, extensors, lateral flexors and rotators) strength were bilaterally assessed (except trunk flexors/extensors) with portable dynamometry by two independent examiners over two sessions (1-2 weeks apart). One-way ANOVAs and intraclass correlation coefficients $\left(\mathrm{ICC}_{2, \mathrm{k}}\right)$ were used for analysis $(\alpha=0.05)$. SEM and $\mathrm{MDD}_{95 \%}$ were also calculated. Results: For all muscular groups and sources of outcome values, including one trial, after familiarization, similar results were found $(0.01 \leq \mathrm{F} \leq 0.08 ; 0.92 \leq p \leq 0.99)$ with significant and adequate values of intra-rater $(0.64 \leq \mathrm{ICC} \leq 0.99 ; 0.23 \leq 95 \% \mathrm{CI} \leq 0.99)$ and inter-rater $(0.66 \leq \mathrm{ICC} \leq 0.99 ; 0.25 \leq 95 \% \mathrm{CI} \leq 0.99)$ reliability. $\mathrm{SEM}$ and $\mathrm{MDD}_{95 \%}$ were considered low $(0.39 \leq \mathrm{EPM} \leq 2.21 \mathrm{Kg}$; $0.96 \leq \mathrm{MMD}_{95 \%} \leq 6.12 \mathrm{Kg}$ ) for all outcome scores. Conclusion: Only one trial, following familiarization, demonstrated adequate intra-rater and inter-rater reliability of the portable dynamometers for the measurement of hand grip, pinch grip and trunk strength in subjects with subacute stroke.
\end{abstract}

Keywords: physical therapy; muscle strength dynamometer; reproducibility of results; stroke.

\section{BULLET POINTS}

- Portable dynamometers present adequate inter and intra-rater reliability in the subacute phase of stroke.

- One trial provides similar results to those obtained with the average of the first two and three trials.

- In clinical practice, one trial can be used to measure hand and trunk muscle strength.

\section{HOW TO CITE THIS ARTICLE}

Aguiar LT, Martins JC, Lara EM, Albuquerque JA, Teixeira-Salmela LF, Faria CDCM. Dynamometry for the measurement of grip, pinch, and trunk muscles strength in subjects with subacute stroke: reliability and different number of trials. Braz J Phys Ther. 2016 Sept-Oct; 20(5):395-404. http://dx.doi.org/10.1590/bjpt-rbf.2014.0173

\section{Introduction}

Hemiparesis, a disability arising from a stroke, with muscle weakness predominant in the hemi-body contralateral to the cerebral lesion, is observed in approximately $77 \%$ of individuals with stroke ${ }^{1-4}$. Muscle weakness is also observed in the hemi-body ipsilateral to the brain lesion and in the torso as a whole ${ }^{5-8}$. Thus, the measurement of muscle strength in post stroke individuals is commonly performed ${ }^{9}$ in different phases of the disease $\mathrm{e}^{10,11}$.

Portable dynamometers are considered a valid instrument for measuring isometric muscular strength - they are easy to use, they provide objective measurements, they are sensitive for detecting changes in muscle strength ${ }^{10,12}$, and they provide suitable

\footnotetext{
${ }^{1}$ Departamento de Fisioterapia, Escola de Educação Física, Fisioterapia e Terapia Ocupacional, Universidade Federal de Minas Gerais (UFMG), 
values of validity and reliability for different muscle groups and populations tested ${ }^{11}$. The intra-rater and inter-rater reliability of portable dynamometers in the measurement of hand grip, pinch grip, and trunk strength was recently investigated in individuals in the chronic phase of stroke ${ }^{13}$, and demonstrated adequate results, with Intraclass Correlation Coefficients (ICC) varying from moderate to very high ${ }^{14}(0.58 \leq \mathrm{ICC} \leq 0.98)$.

Although commonly regarded as a uniform population, subjects with stroke have unique features in each recovery phase (i.e. acute (first three months), subacute (three to six months), and chronic phases ( $\geq$ six months of involvement by stroke) $)^{15-17}$, which may affect the measurement of muscular strength. Motor recovery and the ability to perform functional activities, such as holding an object or sit-to-stand, are examples of these features ${ }^{18,19}$. Therefore, for portable dynamometers to be employed in the subacute phase of stroke, it is necessary to assess measurement properties of these instruments in this population. To our knowledge, only Chen et al. ${ }^{20}$ investigated the reliability of portable dynamometers in individuals in the subacute phase of stroke. However, the authors only assessed intra-rater reliability and only for measurement of handgrip, tripod, and lateral pinch strength. Moreover, the study sample comprised 62 individuals in both subacute and chronic phases of stroke, without separation of the results by phase. According to a recent systematic review, no study has investigated the measurement properties of portable dynamometers to assess hand grip, pinch grip, and trunk strength specifically in the subacute phase of stroke ${ }^{20}$.

Because consistent and reproducible data are essential for credible evaluations, determination of the threshold between error and true change is required for the interpretation of the results. The measurement properties should not be intrinsic characteristics of the measuring instrument ${ }^{21}$. Furthermore, the use of only one trial could facilitate the clinical applicability of the tests. Therefore, the objectives of this study were: (1) to investigate the intra-rater and inter-rater reliabilities of portable dynamometers (SAEHAN ${ }^{\circledR}$ Hydraulic Hand Dynamometer, SAEHAN ${ }^{\circledR}$ Hydraulic Pinch Gauge, and Microfet $2^{\circledR}$ digital manual dynamometer) for the assessment of handgrip, pinch grip (i.e, pulp-to-pulp, tripod, and lateral pinch), and trunk strength; (2) to determine the standard error of the measurement (SEM) and the minimal detectable change (MDC); and (3) to assess whether a different number of trials of measures (i.e. first trial, the average of the first two trials, and the average of three trials) affects the results, in subjects in the subacute phase of stroke.

\section{Method}

\section{Sample}

Individuals from the local community participated in this study. The following inclusion criteria were used: a diagnosis of stroke (subacute phase: between 3 and 6 months since the initial episode $)^{17}$ and age greater than 19 years. Exclusion criteria included those who presented possible cognitive deficits identified by the Mini Mental State Examination based on cutoff points for three levels of education as established by Bertolucci et al. ${ }^{22}$ (i.e. illiterate: 13 points; one to seven years of schooling: 18 points; eight or more years of schooling: 26 points), or the inability to respond to the command "Raise your unaffected arm and open your hand"23, or who had pain or another health condition that affected muscular strength of the hands or trunk.

To determine the number of individuals to be assessed, MedCalc ${ }^{\circledR}$ software, version 12.7.5 (MedCalc Software, Ostend, Belgium) was used, with a sample calculation for a correlation coefficient using power $=0.8, r=0.70$, and $\alpha=0.05$. The result was $n=14$. A prerequisite for use of statistical tests that assess the correlation between variables is the sample variability in relation to the outcome of interest ${ }^{21}$. Taking into account the characteristics that could result in variations in muscle strength, the authors tried to achieve variability in relation to age, sex, and the degree of motor recovery (severe, moderate, or mild) assessed by the Fugl-Meyer Scale for motor function of the Upper Extremity (UE-FM) ${ }^{24}$. Thus, assuming $n=14$ for each of two age groups that could demonstrate variation in muscular strength (20-64 years and over 64 years), $\mathrm{n}=28$ was calculated. Assuming that approximately $15 \%$ of the participants would withdraw on the second day of evaluation, a final sample of $32(28+4[15 \%])$ participants was determined as an attempting to assure sample variability in muscular strength and improve the statistical robustness. However, it is important to point out that the sample size should be at least 14 . Subjects with stroke were included in the present study even though they could not accomplish all muscle groups' assessments. Therefore, once some subjects were not able to activate some muscle groups, the sample size for each muscle group evaluated varied.

Before data collection, the individuals read and signed an Informed Consent Form approved by the Research Ethics Committee at the Universidade Federal de Minas Gerais (UFMG), Belo Horizonte, 
MG, Brazil (ETIC 04 92.0.203.000-10). Clinical and demographic data such as age, sex, type and time since stroke, paretic hand, stage of motor recovery (i.e. on Fugl-Meyer scale) ${ }^{24}$, and trunk performance (i.e. Trunk Impairment Scale) ${ }^{25}$, were collected by a physical therapist with prior experience in the assessment of muscular strength of individuals with stroke in the chronic phase and who was trained to meet the objectives of the present study. The paretic upper extremity (UE) was scored using the Modified Ashworth Scale ${ }^{26}$ using flexors of the elbow, wrist, and fingers, and by the decrease in muscle strength, in comparison with the non-paretic UE. However, unlike the UE-FM, the trunk muscles were not identified in this study as paretic and non-paretic, but as right and left sides. This was done because these muscles receive innervation from both brain hemispheres, although predominantly from the contralateral $\operatorname{side}^{27}$, and also because the trunk motor deficiencies in individuals with stroke can occur on both sides, with compensation by bilateral innervation ${ }^{28}$.

Bilateral muscles strength of handgrip, pinch grip (i.e. pulp-to-pulp, tripod, and lateral), and trunk muscles (i.e. extensors, flexors and lateral flexors, and rotators) were measured by two trained physical therapists (rater-1 and rater-2) with one year of experience in the assessment of muscular strength using a dynamometer. These raters were trained for this assessment by a physical therapist with four years of training and two years of experience in the assessment of muscular strength of post-stroke individuals using portable dynamometers. Training consisted of a detailed explanation and repeated practice procedures for the assessment of strength of the chosen muscle groups using dynamometers. The evaluation of muscle strength for the collection of data was based on a previous study developed for individuals in the chronic phase of stroke, and included the muscle groups evaluated in the present study, with the same instruments and procedures ${ }^{13}$.

\section{Instruments}

The measurement of muscle strength was performed with three portable dynamometers: SAEHAN ${ }^{\circledR}$ Hydraulic Hand Dynamometer Model HS5001 (SAEHAN Corporation, Korea) was used to measure handgrip strength; SAEHAN ${ }^{\circledR}$ Hydraulic Pinch Gauge Model HS5001 was used to measure the 3 pinch grip strengths (i.e.pulp-to-pulp, tripod, and lateral), and Microfet ${ }^{\circledR}$ digital manual dynamometer (Hoggan Health Industries, UT, USA), was used to measure trunk strength. All instruments were new and factory-calibrated according to the manufacturer's information manual.

\section{Procedures}

All assessments of muscle strength were performed following the same procedures adopted by Faria et al. ${ }^{13}$, except for the interval between the two evaluation sessions, which in this study was 1 to 2 weeks ${ }^{17}$. The range of 1 to 2 weeks was adopted as being unlikely to show changes in muscle strength during this period in subjects with subacute stroke ${ }^{17}$. Furthermore, with this interval, the rater would probably not remember the values measured on the first day. The data for intra-rater reliability were obtained by a single rater (rater-1) on two evaluation days, and the data for inter-rater reliability were obtained by two raters (rater-1 and rater-2) on the first evaluation day. An interval of five minutes was provided between measurements by the two raters to prevent muscle fatigue, as previously adopted ${ }^{10}$. The reading and recording of measurements of muscle strength were performed by a recorder, who was also trained. Thus, rater- 1 and rater- 2 had no access to the muscle strength data of the participants. Each rater evaluation lasted in average 20-30 minutes. Therefore, in the first evaluation day the entire muscle strength evaluation lasted around 60 minutes.

The measurements of muscle strength were always obtained in the same order, in an alternating manner, starting with the non-paretic UE and the right side of the trunk. First, a demonstration and familiarization with the equipment and procedures were performed to ensure understanding of the test. Then, three trials at maximum isometric strength were each held for five seconds, and the peak value of the 3 trials was recorded. An interval of 15 to 20 seconds was provided between trials. During the muscle strength test, the rater provided verbal encouragement to the participant to attempt maximum effort.

\section{Statistical analysis}

Descriptive statistics and normality tests (i.e. Shapiro-Wilk) were performed for all outcome measures. One-way analysis of variance (ANOVA) was used to compare all forms of operationalization of measures, taking into account the values obtained by rater- 1 on day- 1 . The $\mathrm{ICC}_{2, \mathrm{k}}$ and $95 \%$ confidence interval (CI) were calculated to determine the intra-rater and inter-rater reliabilities, based on the different forms of operationalization of measures: first trial $\left(\mathrm{ICC}_{2,1}\right)$, the average of the first two trials $\left(\mathrm{ICC}_{2,2}\right)$, and the average of three trials $\left(\mathrm{ICC}_{2,3}\right)$. Significant 
results were classified as follows: very low $=0-0.25$, low $=0.26-0.49$, moderate $=0.50-0.69$, high $=0.70-0.89$, and very high $=0.90-1.00^{14}$.

The stability of the measurements and the amount of change needed to reflect a real difference were determined by using the SEM and MDC based on $95 \% \mathrm{CI}\left(\mathrm{MDC}_{95 \%}\right)$. Both the SEM and $\mathrm{MDC}_{95 \%}$ were calculated according to reliability results and the forms of operationalization of measures ${ }^{21}$. To carry out these analyses, the following formulas were used ${ }^{16}: \mathrm{SEM}=$ standard deviation $\times \sqrt{ }(1-\mathrm{ICC})$; $\mathrm{MDC}_{95 \%}=1.96 \times \mathrm{SEM} \times \sqrt{2}$. The statistical package SPSS version 15.0 (SPSS Inc., Chicago, IL, USA) $(\alpha=0.05)$ was used for the analysis.

\section{Results}

Thirty-two individuals in the subacute phase of stroke (18 men \& 14 women), with a mean age of $63 \pm 12$ years and a mean time following stroke of $3.6 \pm 0.66$ months were assessed (Table 1). Of these 32 , only 24 agreed to participate on the second day of evaluation for work or health reasons.

Table 1. Participant's characteristics of 32 subacute stroke subjects.

\section{Characteristics}

$n=32$

Age (years): mean (SD);

range [min-max]

Time since the onset of stroke (months): mean; range [min-max]

Body mass index $\left(\mathrm{Kg} / \mathrm{m}^{2}\right)$ : mean (SD); range [min-max]

63 (12); [35-85]

$3.6(0.66) ;[3-5]$

25 (4.3); [15-37]

Gender

Men: number (percentage)

$18(56 \%)$

Paretic Side

Right: number (percentage)

Type of stroke

Ischaemic: number (percentage)

$30(94 \%)$

Haemorrhagic: number

(percentage)

Ischaemic and Haemorrhagic:

number (percentage)

Upper Limb Motor Impairment

(Fugl-Meyer Scale). score (0-66)

Mild motor impairments: number (percentage)

$24(75 \%)$

Moderate: number (percentage)

$1(3 \%)$

Severe: number (percentage)

$7(22 \%)$

Trunk Performance scale: median (IQR). score (0-23)
Table 2 presents the results of descriptive statistics, as well as of the ANOVA for comparison of all forms of operationalization of measures for all muscle groups assessed. The values found for all forms of operationalization of measures were similar $(0.01 \leq \mathrm{F} \leq 0.08 ; 0.92 \leq \mathrm{p} \leq 0.99)$.

Tables 3 and 4 present the values of the ICC with the $95 \%$ CI for the intra-rater and inter-rater reliabilities for all muscle groups assessed and forms of operationalization of measures. All measures of intra-rater and inter-rater reliability displayed significant values, classified as moderate to very high $(0.64 \leq \mathrm{ICC} \leq 0.99 ; \mathrm{p} \leq 0.001)$ for all muscle groups (Table 3 and 4 ).

Table 5 presents the results of the SEM and $\mathrm{MDC}_{95 \%}$, based on the intra-rater and inter-rater reliabilities and forms of operationalization of the measures. The values of the SEM and $\mathrm{MDC}_{95 \%}$ were similar between the different forms of operationalization of the measures. All SEM $(0.39 \leq \mathrm{SEM} \leq 2.21 \mathrm{Kg})$ and $\mathrm{MDC}_{95 \%}\left(0.96 \leq \mathrm{MMD}_{95 \%} \leq 6.12 \mathrm{Kg}\right)$ values are presented in Table 5.

\section{Discussion}

The portable dynamometers presented adequate intra-rater and inter-rater reliabilities for measurement of grip, pinch, and trunk muscular strength in individuals in the subacute phase of stroke, with low values of SEM and MDC. In general, the $95 \%$ CI of the ICC for intra-rater and inter-rater reliabilities displayed adequate values. Moreover, results obtained with one trial were similar to those obtained with the average of the first two and three trials.

As the ICC is the most appropriate method for analyzing reliability, only studies that used the ICC were used in this discussion. Faria et al. ${ }^{13}$ investigated the intra-rater and inter-rater reliabilities of portable dynamometers in assessing the strength of the same muscle groups evaluated in this study, but with individuals in the chronic phase of stroke. The results of the reliabilities in the chronic phase of stroke were classified as moderate to very high $(0.58 \leq \mathrm{ICC} \leq 0.98)^{13}$. These results are similar to those of the present study: $(0.64 \leq$ ICC $\leq 0.99)$. It was not possible to compare the $95 \% \mathrm{CI}$ of the ICC with the study of Faria et al. ${ }^{13}$ because that analysis was not reported. Chen et al. ${ }^{20}$, with a sample of individuals in the subacute and chronic phases grouped together, reported an ICC classified as very high $(0.96 \leq \mathrm{ICC} \leq 0.98 ; 0.93 \leq 95 \% \mathrm{CI} \leq 0.99)$ when evaluating handgrip strength, tripod pinch, and 
Table 2. Results of descriptive statistics (means \pm SD) and ANOVA regarding the comparisons between the various sources of outcome scores for muscular strength measurement of both the non-paretic and paretic upper extremities and trunk with portable dynamometry $(\mathrm{Kg})$ for 32 subacute stroke subjects.

\begin{tabular}{|c|c|c|}
\hline Muscular groups ( $n$ ) & First trial & $\begin{array}{l}\text { Mean of two } \\
\text { first trials }\end{array}$ \\
\hline
\end{tabular}

Non-paretic upper extremity

\begin{tabular}{|c|c|c|c|c|}
\hline Hand grip (25) & $28.12 \pm 10.48$ & $27.76 \pm 10.45$ & $27.41 \pm 10.29$ & $0.03 ; 0.98$ \\
\hline Pulp-to-pulp pinch (23) & $4.25 \pm 1.63$ & $4.22 \pm 1.55$ & $4.20 \pm 1.51$ & $0.02 ; 0.98$ \\
\hline Tripod pinch (23) & $5.63 \pm 2.31$ & $5.58 \pm 2.03$ & $5.56 \pm 1.92$ & $0.01 ; 0.99$ \\
\hline Lateral pinch (23) & $7.09 \pm 2.10$ & $7.27 \pm 2.01$ & $7.22 \pm 1.97$ & $0.02 ; 0.98$ \\
\hline \multicolumn{5}{|l|}{ Paretic upper extremity } \\
\hline Hand grip (18) & $26.31 \pm 9.86$ & $25.62 \pm 9.97$ & $25.54 \pm 10.06$ & $0.01 ; 0.99$ \\
\hline Pulp-to-pulp pinch (17) & $4.08 \pm 1.44$ & $3.88 \pm 1.54$ & $3.89 \pm 1.56$ & $0.01 ; 0.99$ \\
\hline Tripod pinch (17) & $4.88 \pm 2.29$ & $5.02 \pm 2.22$ & $4.94 \pm 2.09$ & $0.04 ; 0.97$ \\
\hline Lateral pinch (19) & $6.32 \pm 2.84$ & $6.16 \pm 2.77$ & $6.11 \pm 2.72$ & $0.01 ; 0.99$ \\
\hline \multicolumn{5}{|l|}{ Trunk } \\
\hline Anterior trunk flexors (20) & $9.39 \pm 3.48$ & $9.28 \pm 3.56$ & $9.25 \pm 3.48$ & $0.01 ; 0.99$ \\
\hline Trunk extensors $(20)$ & $10.26 \pm 3.23$ & $10.16 \pm 3.12$ & $9.87 \pm 3.25$ & $0.08 ; 0.92$ \\
\hline Right lateral trunk flexors (20) & $8.32 \pm 2.85$ & $8.35 \pm 2.96$ & $8.51 \pm 2.99$ & $0.03 ; 0.98$ \\
\hline Left lateral trunk flexors (20) & $8.43 \pm 2.76$ & $8.64 \pm 2.73$ & $8.62 \pm 2.74$ & $0.04 ; 0.97$ \\
\hline Right trunk rotators $(20)$ & $7.71 \pm 2.58$ & $7.46 \pm 2.51$ & $7.44 \pm 2.56$ & $0.07 ; 0.93$ \\
\hline Left trunk flexors (20) & $7.46 \pm 2.69$ & $7.34 \pm 2.65$ & $7.22 \pm 2.58$ & $0.04 ; 0.96$ \\
\hline
\end{tabular}

SD: Standard deviation.

Table 3. Intra-class correlation coefficients (ICC) and $95 \%$ confidence interval (CI) for the intra-rater reliability for muscular strength measurement of both the non-paretic and paretic upper extremities and trunk with portable dynamometers (Kg) considering various sources of outcome scores for 24 subacute stroke patients.

\section{Muscular groups}

(n)

\section{Non-paretic upper extremity \\ Hand grip (17) \\ Pulp-to-pulp pinch (16) \\ Tripod pinch (16) \\ Lateral pinch (16)}

\section{Paretic upper extremity \\ Hand grip (13) \\ Pulp-to-pulp pinch (12) \\ Tripod pinch (12) \\ Lateral pinch (14)}

\section{Trunk}

Anterior trunk flexors (20)

Trunk extensors (20)

Right lateral trunk flexors (20)

Left lateral trunk flexors (20)

Right trunk rotators (20)

Left trunk rotators (20)

${ }^{*} p \leq 0.001$. ${ }^{* *} p=0.003$.

\section{Intra-rater reliability}

Mean of two first trials

$$
\text { ICC }_{2.2}[95 \% \mathrm{CI}]
$$

Mean of three trials

$$
\text { ICC }_{2.1}[95 \% \mathrm{CI}]
$$

$0.95 *$ [0.87-0.98]

$0.98 *$ [0.94-0.99]

0.99* [0.96-0.99]

$0.64 * *[0.23-0.86]$

$0.83 *$ [0.50-0.94]

$0.85 *$ [0.57-0.95]

$0.84 *$ [0.60-0.94]

$0.93 *[0.80-0.98]$

$0.95 *$ [0.85-0.98]

$0.84 *[0.60-0.94]$

$0.93 *[0.79-0.98]$

0.94* [0.84-0.98]

ICC $_{2.3}[95 \% \mathrm{CI}]$

$0.97 *$ [0.90-0.99]

$0.99 *[0.96-0.99]$

$0.98 *$ [0.95-0.99]

$0.82 *$ [0.51-0.95]

$0.89 *[0.63-0.97]$

$0.90 *$ [0.67-0.97]

$0.85 *[0.57-0.91]$

$0.95 *$ [0.81-0.98]

$0.95 *$ [0.81-0.98]

$0.91 *[0.74-0.97]$

$0.95 *$ [0.85-0.99]

$0.96 *$ [0.88-0.99]

$0.87 *[0.71-0.95]$
$0.79 *[0.55-0.91]$
$0.84 *[0.51-0.94]$
$0.88 *[0.72-0.95]$
$0.77 *[0.39-0.91]$
$0.74 *[0.46-0.89]$

$0.94 *[0.85-0.98]$

0.94* [0.85-0.98]

$0.89 *[0.70-0.96]$

$0.90 *$ [0.71-0.96]

$0.94 *$ [0.84-0.98]

$0.96 *$ [0.89-0.98]

$0.96 *$ [0.90-0.98]

$0.96 *$ [0.90-0.98]

$0.89 *[0.69-0.96]$

$0.89 *$ [0.72-0.96]

$0.92 *[0.79-0.97]$

0.94* [0.84-0.98] 
Table 4. Intra-class correlation coefficients (ICC) and 95\% confidence interval (CI) for the inter-rater reliability for muscular strength measurement of both the non-paretic and paretic upper extremities and trunk with portable dynamometers (Kg) considering various sources of outcome scores for 32 subacute stroke patients.

\begin{tabular}{|c|c|c|c|}
\hline$\underset{(n)}{\text { Muscular groups }}$ & $\begin{array}{c}\text { First trial } \\
\text { ICC }_{2.1}[95 \% \mathrm{CI}]\end{array}$ & $\begin{array}{l}\text { Inter-rater reliability } \\
\text { Mean of two first trials } \\
\text { ICC }_{2.2}[95 \% \mathrm{CI}]\end{array}$ & $\begin{array}{l}\text { Mean of three trials } \\
\text { ICC }_{2.3}[95 \% \mathrm{CI}]\end{array}$ \\
\hline \multicolumn{4}{|l|}{ Non-paretic upper extremity } \\
\hline Hand grip (24) & $0.95 *[0.89-0.98]$ & $0.98 *[0.95-0.99]$ & $0.98 *[0.96-0.99]$ \\
\hline Pulp-to-pulp pinch (22) & $0.70 *[0.41-0.87]$ & $0.84 *[0.61-0.93]$ & $0.85 *[0.64-0.94]$ \\
\hline Tripod pinch (22) & $0.86 *[0.69-0.94]$ & $0.94 *[0.85-0.97]$ & $0.95 *[0.88-0.98]$ \\
\hline Lateral pinch (22) & $0.91 *[0.80-0.96]$ & $0.93 *[0.84-0.97]$ & $0.95 *[0.88-0.98]$ \\
\hline \multicolumn{4}{|l|}{ Paretic upper extremity } \\
\hline Hand grip (18) & $0.95 *[0.88-0.98]$ & $0.98 *[0.95-0.99]$ & $0.99 *[0.96-0.99]$ \\
\hline Pulp-to-pulp pinch (17) & $0.70 *[0.34-0.88]$ & $0.92 *[0.78-0.97]$ & $0.94 *[0.83-0.98]$ \\
\hline Tripod pinch (17) & $0.88^{*}[0.69-0.95]$ & $0.94 *[0.84-0.98]$ & $0.94 *[0.84-0.98]$ \\
\hline Lateral pinch (18) & $0.88 *[0.72-0.96]$ & $0.93 *[0.80-0.97]$ & $0.95 *[0.85-0.98]$ \\
\hline \multicolumn{4}{|l|}{ Trunk } \\
\hline Anterior trunk flexors (26) & $0.76^{*}[0.37-0.90]$ & $0.90 *[0.59-0.96]$ & $0.91 *[0.52-0.97]$ \\
\hline Trunk extensors (26) & $0.66 *[0.14-0.86]$ & $0.84 *[0.25-0.95]$ & $0.84 *[0.21-0.95]$ \\
\hline Right lateral trunk flexors (25) & $0.87 *[0.74-0.94]$ & $0.92 *[0.79-0.97]$ & $0.87 *[0.64-0.95]$ \\
\hline Left lateral trunk flexors (25) & $0.70 *[0.33-0.87]$ & $0.85 *[0.61-0.94]$ & $0.85 *[0.59-0.94]$ \\
\hline Right trunk rotators $(25)$ & $0.73 *[0.22-0.90]$ & $0.83 *[0.41-0.94]$ & $0.85 *[0.49-0.94]$ \\
\hline Left trunk rotators $(25)$ & $0.78 *[0.52-0.90]$ & $0.87 *[0.70-0.95]$ & $0.89 *[0.76-0.95]$ \\
\hline
\end{tabular}

$* p \leq 0.001$.

lateral pinch. The result of the present study was similar to that of Chen et al. ${ }^{20}$ for the same muscle groups and forms of operationalization (average of three trials) $(0.94 \leq \mathrm{ICC} \leq 0.99 ; 0.81 \leq 95 \% \mathrm{CI} \leq 0.99)$. With regard to the use of different forms of operationalization of the measures, the results of the present study were also similar to several published studies with individuals in the chronic phase of stroke ${ }^{13,29-32}$. In these studies, only one trial, after familiarization, presented similar results for the measurement properties investigated and for the values obtained when compared to other forms of operationalization, except for the measurement of the plantar flexor muscle strength of the non-paretic side using the Modified Sphygmomanometer Test (MST) measured by two raters. Nevertheless, the present study is the first to consider a sample of individuals in the subacute phase of stroke.

All SEM values in this study were below $2.21 \mathrm{Kg}$, indicating that the measurement of muscular strength by portable dynamometers was able to distinguish between small real changes in muscle strength and error in individuals in the subacute phase of stroke. In addition, the results of the SEM were similar to those reported by Bertrand et al. ${ }^{33}$ and Boissy et al..$^{34}$, who determined the SEM of handgrip muscular strength with a dynamometer, allowing for ICC values of intra-rater reliability, in individuals in the chronic phase of stroke. The MDC indicates the least amount of change that can be interpreted as either real improvement or worsening ${ }^{21}$. The MDC values in this study varied from 0.96 to $6.12 \mathrm{Kg}$. Therefore, for a change in muscle strength to be considered real after an intervention, when evaluated using portable dynamometers, one must have changes equal to or greater than 0.96 to $6.12 \mathrm{Kg}$ (depending on the muscle group and the number of trials performed). No study was found that investigated the MDC to evaluate muscular strength with a dynamometer in subjects with stroke. However, the values of MDC found were similar to those of healthy individuals (MDC=5.7 and 7.1 Kg), and were lower than the values of individuals hospitalized in intensive care units (MDC=7.8 and $12.5 \mathrm{Kg}$ ), whose handgrip strength was evaluated using a dynamometer (average of three trials), taking into account test-test reliability ${ }^{35,36}$. The MDC values should be used in interpretation of the 


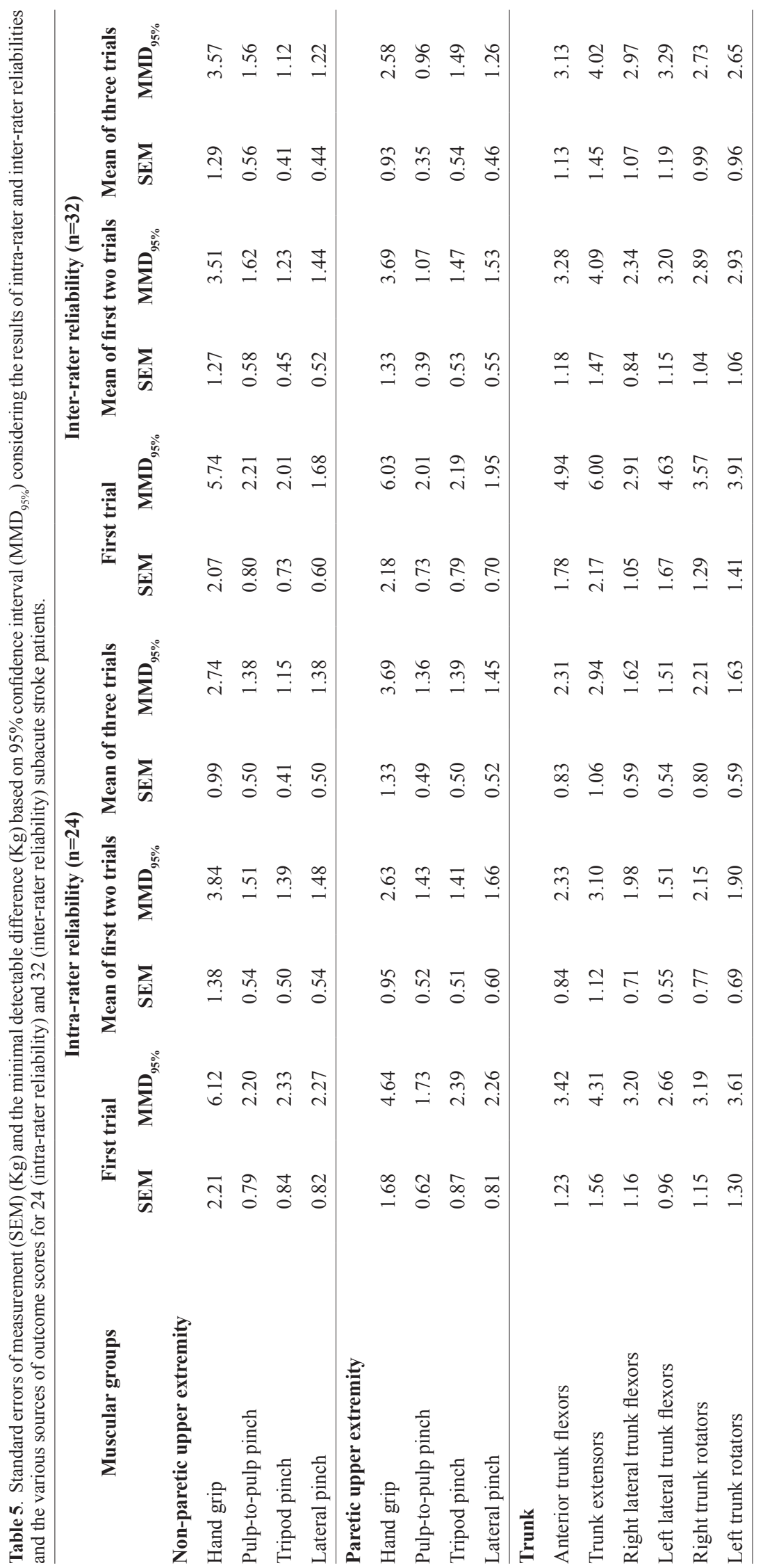


measurements of muscle strength using dynamometers in subjects with stroke.

One of the limitations of this study was the fact that the sample comprised few individuals with moderate/ severe motor involvement, and had more individuals with the mean time following the stroke closer to three than six months. In addition, three measures of intra-rater reliability on the paretic side (handgrip, pulp-to-pulp, and tripod pinch) had a sample size smaller than 14 , the minimum value estimated by the sample size calculation, as it was not possible to reassess the ability of some study participants to exert force with these muscle groups. However, the values of intra-rater reliability for these measures were classified as high to very high $(0.82 \leq \mathrm{ICC} \leq 0.97)$, and the SEM and MDC were not different. Another limitation was the 1-2-week interval between the two evaluations days used to determine the intra-rater reliability, even in individuals receiving rehabilitation. Although the authors did not expect changes in muscle strength in the subacute phase of stroke within this interval, the fact that some individuals were in rehabilitation programs could potentially have modified muscle strength and influenced the results of intra-rater reliability. Nevertheless, the authors emphasize that the results were satisfactory for intra-rater reliability, which suggests that this possible influence did not occur or undermine the results. In addition, to ensure the internal validity of the study, a recorder was included to perform the reading and recording of values, which is not common in clinical practice. Finally, the sample loss on the second day of evaluation was greater than expected, and only 24 individuals were evaluated on the second day. However, this sample size is higher than the minimum sample size value $(n=14)$. In addition, the values of the intra-rater reliability for all the measures were classified as high to very high $(0.74 \leq \mathrm{ICC} \leq 0.99)$, except for the first trial of the non-paretic pulp-to-pulp pinch that was classified as moderate $(\mathrm{ICC}=0.64)$, which is also considered as adequate.

The portable dynamometers presented adequate reliability in the subacute phase of stroke, and therefore, can be used in clinical practice to measure muscle strength in these individuals if the individuals are able to do the tests. In addition, only one trial measurement of handgrip, pinch, and trunk strength is adequate. The use of only one trial has the advantage of requiring a shorter evaluation period, reducing possible effects of fatigue, loss of attention, and discomfort. In this specific population, the possibility of using only one trial after familiarization is even more important due to the characteristics of the muscle fatigue or an inability to do the test commonly observed ${ }^{32}$. Moreover, the MDC presented in this study could be used to decide whether a change in muscle strength is real.

\section{Conclusion}

The portable dynamometers presented adequate inter-rater and intra-rater reliability for the measurement of handgrip, pinch grip (i.e. pulp-to-pulp, tripod, and lateral pinch), and trunk muscle strength in individuals in the subacute phase of stroke, with the use of only one trial after familiarization. The values associated with the SEM and MDC were low and should be used for drawing conclusions when evaluating muscle strength in this population.

\section{References}

1. Go AS, Mozaffarian D, Roger VL, Benjamin EJ, Berry JD, Borden WB, et al. Heart disease and stroke statistics-2013 update: a report from the American Heart Association. Circulation. 2013;127(1):6-245. http://dx.doi.org/10.1161/ CIR.0b013e31828124ad.

2. Lawrence ES, Coshall C, Dundas R, Stewart J, Rudd AG, Howard R, et al. Estimates of the prevalence of acute stroke impairments and disability in a multiethnic population. Stroke. 2001;32(6):1279-84. http://dx.doi.org/10.1161/01. STR.32.6.1279. PMid:11387487.

3. LeBrasseur NK, Sayers SP, Ouellette MM, Fielding RA. Muscle impairments and behavioral factors mediate functional limitations and disability following stroke. Phys Ther. 2006;86(10):1342-50. http://dx.doi.org/10.2522/ ptj.20050162. PMid:17012638.

4. Nakayama H, Jorgensen $H$, Raaschou H, Olsen $T$. Compensation in recovery of upper extremity function after stroke: the Copenhagen Stroke Study. Arch Phys Med Rehabil. 1994;75(8):852-7. http://dx.doi.org/10.1016/00039993(94)90108-2. PMid:8053790.

5. Kitsos GH, Hubbard IJ, Kitsos AR, Parsons MW. The ipsilateral upper limb can be affected following stroke. ScientificWorldJournal. 2013;26:684-860. PMid:24379748.

6. Metrot J, Froger J, Hauret I, Mottet D, van Dokkum L, Laffont I. Motor recovery of the ipsilateral upper limb in subacute stroke. Arch Phys Med Rehabil. 2013;94(11):2283-90. http:// dx.doi.org/10.1016/j.apmr.2013.05.024. PMid:23796686.

7. Silva P, Franco J, Gusmão A, Moura J, Teixeira-Salmela L, Faria C. Trunk strength is associated with sit-to-stand perfomance in both stroke and healthy subjects. Eur J Phys Rehabil Med. 2015;51(6):717-24. PMid:25673183.

8. Karthikbabu S, Chakrapani M, Ganeshan S, Rakshith KC, Nafeez S, Prem V. A review on assessment and treatment of the trunk in stroke: a need or luxury. Neural Regen Res. 2012;7(25):1974-7. PMid:25624827. 
9. Tyson S, Watson A, Moss S, Troop H, Dean-Lofthouse G, Jorritsma S, et al. Development of a framework for the evidence-based choice of outcome measures in neurological physiotherapy. Disabil Rehabil. 2008;30(2):142-9. http:// dx.doi.org/10.1080/09638280701216847. PMid:17852285.

10. Martins J, Teixeira-Salmela L, Aguiar L, Souza L, Lara E, Faria CDCM. Assessment of the strength of the trunk and upper limb muscles in stroke subjects with portable dynamometry: a literature review. Phys Ther Movement. 2015;28(1):169-86.

11. Souza LAC, Martins JC, Teixeira-Salmela LF, Godoy MR, Aguiar LT, Faria CDCM. Evaluation of muscular strength with the modified sphygmomanometer test: a literature review. Fisioter Mov. 2013;26(2):437-52. http://dx.doi. org/10.1590/S0103-51502013000200021.

12. Stark T, Walker B, Phillips J, Fejer R, Beck R. Hand-held dynamometry correlation with the gold standard isokinetic dynamometry: a systematic review. PM R. 2011;3(5):472-9. http://dx.doi.org/10.1016/j.pmrj.2010.10.025. PMid:21570036.

13. Faria CDCM, Aguiar L, Lara E, Souza L, Martins J, TeixeiraSalmela L. Dynamometry for the assessment of grip, pinch, and trunk strength in subjects with chronic stroke: reliability and various sources of outcome values. Int $\mathrm{J}$ Phys Med Rehabil. 2013;1(8):1-5.

14. Munro B. Correlation. In: Munro B, editor. Statistical methods for health care research. 5th ed. Philadelphia: Lippincott Williams \& Wilkins; 2005. p. 239-58.

15. Cramer SC. Repairing the human brain after stroke: I. Mechanisms of spontaneous recovery. Ann Neurol. 2008;63(3):272-87. http://dx.doi.org/10.1002/ana.21393. PMid:18383072.

16. Krakauer J. Motor learning: its relevance to stroke recovery and neurorehabilitation. Curr Opin Neurol. 2006;19(1):8490. http://dx.doi.org/10.1097/01.wco.0000200544.29915.cc. PMid:16415682.

17. Kwakkel G, Kollen BJ. Predicting activities after stroke: what is clinically relevant? Int J Stroke. 2013;8(1):2532. http://dx.doi.org/10.1111/j.1747-4949.2012.00967.x. PMid:23280266.

18. Mirbagheri MM, Rymer WZ. Time-course of changes in arm impairment after stroke: variables predicting motor recovery over 12 months. Arch Phys Med Rehabil. 2008;89(8):1507-13. http://dx.doi.org/10.1016/j.apmr.2008.02.017. PMid:18586221.

19. Guimarães RM, Pereira JS, Batista LA. Soleus muscle strengthening: impact on gait kinematics of hemiparetic subjects. Fisioter Mov. 2007;20(3):11-6.

20. Chen HM, Chen CC, Hsueh I, Huang SL, Hsieh CL. Test-retest reproducibility and smallest real difference of 5 hand function tests in patients with stroke. Neurorehabil Neural Repair. 2009;23(5):435-40. http://dx.doi.org/10.1177/1545968308331146. PMid:19261767.

21. Portney LG, Watkins MP. Foundations of clinical research: applications to practice. 3rd ed. New Jersey: Prentice-Hall; 2009.

22. Bertolucci PHF, Brucki SMD, Campacci SR, Juliano Y. The Mini-Mental State Examination in a general population: impact of educational status. Arq Neuropsiquiatr. 1994;52(1):17. http://dx.doi.org/10.1590/S0004-282X1994000100001. PMid:8002795.
23. Teixeira-Salmela LF, Devaraj R, Olney SJ. Validation of the human activity profile in stroke: a comparison of observed, proxy and self-reported scores. Disabil Rehabil. 2007;29(19):1518-24. http://dx.doi.org/10.1080/09638280601055733. PMid:17852225.

24. Michaelsen S, Rocha A, Knabben R, Rodrigues L, Fernandes C. Tradução, adaptação e confiabilidade interexaminadores do manual de administração da escala de Fugl-Meyer. Braz J Phys Ther. 2011;15(1):80-8. http://dx.doi.org/10.1590/ S1413-35552011000100013.

25. Verheyden G, Nieuwboer A, Mertin J, Preger R, Kiekens C, De Weerdt W. Trunk Impairment Scale: a new tool to measure motor impairment of the trunk after stroke. Clin Rehabil. 2004;18(3):326-34. http://dx.doi.org/10.1191/0269215504cr733oa. PMid:15137564.

26. Brashear A, Zafonte R, Corcoran M, Galvez-Jimenez N, Gracies J, Gordon M, et al. Inter- and intrarater reliability of the ashworth scale and the disability assessment scale in patients with upper-limb poststroke spasticity. Arch Phys Med Rehabil. 2002;83(10):1349-54. http://dx.doi.org/10.1053/ apmr.2002.35474. PMid:12370866.

27. Hsieh CL, Sheu CF, Hsueh I, Wang CH. Trunk control as an early predictor of comprehensive activities of daily living function in stroke patients. Stroke. 2002;33(11):2626-30. http://dx.doi.org/10.1161/01.STR.0000033930.05931.93. PMid:12411652.

28. Karthikbabu S, Chakrapani M, Ganeshan S, Rakshith KC, Nafeez S, Prem V. A review on assessment and treatment of the trunk in stroke: a need or luxury. Neural Regen Res. 2012;7(25):1974-7. PMid:25624827.

29. Faria CD, Teixeira-Salmela LF, Gomes M No, Rodriguesde-Paula F. Performance-based tests in subjects with stroke: outcome scores, reliability and measurement erros. Clin Rehabil. 2012;26(5):460-9. http://dx.doi. org/10.1177/0269215511423849. PMid:22008883.

30. Martins J, Teixeira-Salmela L, Souza L, Aguiar L, Lara E, Moura J, et al. Validity and reliability of the modified sphygmomanometer test to assess strength of the upper limbs after stroke. J Rehabil Med. 2015. http://dx.doi. org/10.2340/16501977-1978.

31. Souza LA, Martins JC, Teixeira-Salmela LF, Lara EM, Moura JB, Aguiar LT, et al. Validity and reliability of the modified sphygmomanometer test to assess strength of the lower limb and trunk muscles after stroke. J Rehabil Med. 2014;46(7):620-8. http://dx.doi.org/10.2340/16501977-1823. PMid:24849895.

32. Pinheiro MB, Scianni AA, Ada L, Faria CDCM, TeixeiraSalmela LF. Reference values and psychometric properties of the lower extremity motor coordination test. Arch Phys Med Rehabil. 2014;95(8):1490-7. http://dx.doi.org/10.1016/j. apmr.2014.03.006. PMid:24681388.

33. Bertrand AM, Mercier C, Bourbonnais D, Desrosiers J, Gravel D. Reliability of maximal static strength measurements of the arms in subjects with hemiparesis. Clin Rehabil. 2007;21(3):248-57. http://dx.doi.org/10.1177/0269215506070792. PMid:17329282.

34. Boissy P, Bourbonnais D, Carlotti MM, Gravel D, Arsenault BA. Maximal grip force in chronic stroke subjects and its relationship to global upper extremity function. Clin Rehabil. 1999;13(4):354-62. http://dx.doi. org/10.1191/026921599676433080. PMid:10460123. 
35. Baldwin CE, Paratz JD, Bersten AD. Muscle strength assessment in critically ill patients with handheld dynamometry: an investigation of reliability,minimal detectable change, and time to peak force generation. J Crit Care. 2013;28(1):77-86. http://dx.doi.org/10.1016/j.jcrc.2012.03.001. PMid:22520490.

36. Horstman AM, Gerrits KH, Beltman MJ, Koppe PA, Janssen TW, de Haan A. Intrinsic properties of the knee extensor muscles after subacute stroke. Arch Phys Med Rehabil. 2010;91(1):123-8. http://dx.doi.org/10.1016/j.apmr.2009.09.008. PMid:20103406.

\section{Correspondence}

Christina Danielli Coelho de Morais Faria

Universidade Federal de Minas Gerais

Departamento de Fisioterapia

Avenida Antonio Carlos, 6627, Campus Pampulha CEP 31270-901, Belo Horizonte, MG, Brazil

e-mail: cdcmf@ufmg.br, chrismoraisf@yahoo.com 